\title{
Controlling relationships in preschool children
}

\author{
José Manuel Muñoz \\ Universidad de Cádiz, Spain
}

\author{
Francisco Braza \\ Estación Biológica de Doñana (CSIC), \\ Sevilla, Spain
}

\author{
Rosario Carreras \\ Universidad de Cádiz, Spain
}

\begin{abstract}
In order to facilitate the comprehension of social structure in preschool children, our research has two foci: first, to define controlling behaviours (nonaggressive group organisation) and to determine their organisational principles, and second, to analyse the relation of the controlling behaviours with aggressive behaviours. Through direct observation, the behaviour of 90 preschoolers aged 4-5 years old during free playtime was registered. A correspondence analysis revealed that two organisational principles structure controlling relationships, one related to authority and another to acquiescence. The independence of these two dimensions suggests the existence of a social hierarchy in preschoolers' playgroups based on controlling behaviour. No significant relation between authoritative and aggressive behaviours in 4-year-old children was detected, while 5-year-old children with high levels of authoritative behaviour were less aggressive than individuals with low levels. Our results point out that controlling activity is relevant in the organisation of preschool children's social groups. Children's goal development probably determines the change of the behavioural strategies that facilitate the evolution of social structure from aggressive to controlling hierarchies. We judge it necessary for research to focus on controlling interactions.
\end{abstract}

\section{Introduction}

In the study of the organisation of preschool social groups, most authors have focused on the analysis of the dominance relationships that appear as a result of children's aggressive interactions (Bernstein, 1981; Hold, 1977; LaFreniere \& Charlesworth, 1983; McGrew, 1972a; Sluckin \& Smith, 1977; Strayer, Chapeskie, \& Strayer, 1978; Strayer \& Strayer, 1976; Vaughn \& Waters, 1981).

However, Tinbergen (1953) had already denoted the limitations of using aggression as the only explicative element of group organisation. Indeed, as Pellegrini (2002) pointed out in the organisation of preschool social groups both aggressive and nonaggressive behaviours are implied (Archer, 1992; Boulton \& Smith, 1990; Pettit, Bakshi, Dodge, \& Coie, 1990, Vaughn \& Waters, 1981). Other authors have emphasised that the abilities to gain the other's attention or to organise the group's activities, e.g., giving directions or giving orders, are more relevant than aggressive behaviours for group structure (Edwards, 1994; Fukada, Fukada, \& Hicks, 1994, 1997). We will name these nonaggressive activities, which lead to the organisation of group activities into the group, as controlling activities.

In previous studies, we have observed social behaviour in preschool children during free playtime using a wide catalogue of behaviours (Carreras, 1999; Muñoz, 2000). By analysing the frequency of the different behaviours, we have observed in our studies that preschool children display controlling behaviours more frequently than aggressive behaviours during free playtime, although both kind of activities are less frequent than affiliative and play activities (Muñoz, 2000). These results are no different from those obtained by researchers from other study samples (Blurton Jones, 1967, 1971, 1972; Brannigan \& Humphries, 1972; Howes, 1990; McGrew, 1972b; Smith \& Connolly, 1972; Smith \& Lewis, 1985; Strayer, 1980).

We are interested in determining the principles that organise controlling behaviours by analysing the sequence in which these activity patterns appear, when exhibited by children during free playtime. Furthermore, we consider it interesting to explore, as a second aim, the relation between controlling and aggressive behaviours, taking into account that both are implied in group organisation.

\section{Materials and methods}

We have chosen an observational method in order to record the children's social behaviour during free playtime at school during an academic year. Children were filmed at least twice a week during the central 15 minutes of the daily half-hour of free playtime at school. Filmed children were unaware of the observers, who had previously obtained permission from parents and teachers. The playground was an open-air area of $190 \mathrm{~m}^{2}$.

In Tables 1 and 2, we define with more detail the controlling and aggressive behaviours considered. Behaviour was recorded using focal sampling and continuous recording methods (Martin \& Bateson, 1986). The filmed groups were selected at random, and the behaviour of each child of the group was analysed sequentially (total sequences analysed = 1305). To contribute to the independence of the data, no child was filmed excessively (from a minimum of 15 seconds to a maximum of 60 seconds). The analysis and quantification of the behavioural patterns were accomplished with a Phillips 
Table 1

Behaviours related to control

Behaviours Short description

Give order (GO)

Lead (LE)

Show Object $(\mathrm{SH})$

Reorientation (RE)

Point (PO)

Obey order (OB)

Follow (FO)

Look at object (LO)

Allow reorientation (AR)

Look at point (LP)
$\mathrm{S}$ gestures for $\mathrm{R}$ to carry out a specific activity.

$\mathrm{S}$ walks while $\mathrm{R}$ follows no further than 2 metres. Physical contact between $\mathrm{S}$ and $\mathrm{R}$ is unnecessary.

$\mathrm{S}$ holds an object and extends his arm, with elbows slightly bent, towards $\mathrm{R}$. The object should move from $\mathrm{S}$ toward $\mathrm{R}$, although not necessarily crossing the imaginary line between them.

$\mathrm{S}$ changes R's position with one or two hands. The reorientation may take place while in motion or stationary, and always implies physical contact between $\mathrm{S}$ and $\mathrm{R}$.

$\mathrm{S}$ extends his arm, totally or partially, with the index finger extended towards a point, object, or person, near or far, forming an imaginary line between the two. S's head is generally inclined in the direction of this line and the other arm remains by his side. Also included are attempts by $S$ to point using the chin.

$S$ performs R's orders.

$\mathrm{S}$ moves behind $\mathrm{R}$, following the same trajectory and at a constant distance.

$\mathrm{S}$ looks in the direction of the object that $\mathrm{R}$ shows.

$\mathrm{S}$ changes his/her position according to R's reorientation.

$\mathrm{S}$ fixes on some point that $\mathrm{R}$ has previously indicated. $\mathrm{S}$ and $\mathrm{R}$ remain close.
VR302 video-cassette recorder and an IBM compatible personal computer, using custom-designed software based on a personal program written in FoxPro (Microsoft software). To analyse the data, a minimum of two authors recorded the behaviour of each member of the focus peer group, from the videotape, obtaining an inter-observer mean agreement above $90 \%$ for all behaviours.

\section{Objective 1}

In order to determine the principles that organise the controlling behaviours, a total of 90 preschool children (from 3.8 to 5.8 years; mean $=4.9 \pm 0.6 ; 58$ girls, 32 boys) from Cádiz (Spain) were selected. Considering that in a previous study (Braza, Braza, Carreras, \& Muñoz, 1997) we did not find any activity performed only by girls or boys, we have pooled the information of all the subjects from both sexes for the purpose of analysis.

From each of the sequences registered, a transitional matrix (two-way frequency matrix) with the frequencies of the observed behavioural patterns was performed, containing the preceding controlling activities in rows and the following controlling activities in columns. Afterwards, a total matrix was calculated using the sum of the transitional matrices from all the subjects. Once the total matrix was obtained, a correspon-

Table 2

Behaviours related to aggressive activities

\begin{tabular}{ll}
\hline Behaviours & Short description \\
\hline Threaten & $\begin{array}{l}\text { Threatening gestures or intentional move- } \\
\text { ments of attack. }\end{array}$ \\
Argue & $\begin{array}{l}\text { Verbal or gestural abuse without physical } \\
\text { contact. }\end{array}$ \\
Smack & S pushes R trying to enlarge their distance. \\
Avoid robbery & S stops R from getting something belonging to \\
Try to take object & S. \\
Take object & R.
\end{tabular}

dence analysis was performed in searching for a classification of the controlling activities.

The correspondence analysis is a new method in the study of behavioural structure in preschool children. This analysis has been applied successfully in several studies with similar aims than ours (Thon \& Chabaud, 1986; Van der Heijden, 1986; Van der Heijden, De Vries, \& Van Hooff, 1990). The correspondence analysis allows a multidimensional representation of the association between the preceding (in rows) and the following (in columns) behaviours. Correspondence analysis uses a chi-square distance as a similarity measure that is more suitable, both in methodological and ethological terms, than other exploratory methods (i.e., principal components, factor analysis) that use correlation coefficients as measures of association among behavioural patterns. Using correlations as a measure to describe the association between two variables presupposes that these variables follow a bivariate normal distribution, and there is no basis for this assumption in behavioural transitional patterns. For more detailed information about the procedure, see Van der Heijden et al., 1990.

\section{Objective 2}

In this part of the study we shall explore the relations between controlling and aggressive behaviour, both of which are implicated in the group organisation at preschool age. Given that previous research suggests a decline in aggressive behaviour across the preschool period (for a review see Coie \& Dodge, 1998), we consider it interesting to examine the relations between controlling and aggressive behaviour with respect to the age of the children. Thus, in the study sample, we have considered two subgroups of children; one composed of thirty 4-year-old children (mean $=4.14 \pm 0.25$ ) and the other with sixty 5 -year-old children (mean $=5.28 \pm 0.29$ ).

\section{Results}

\section{Organisational principles of controlling activities}

For the correspondence analysis, we first had to check the possibility that the controlling activities were independent from each other. In our case the deviation from independence is highly significant, $\chi^{2}(121)=164.8 ; p<.001$. 


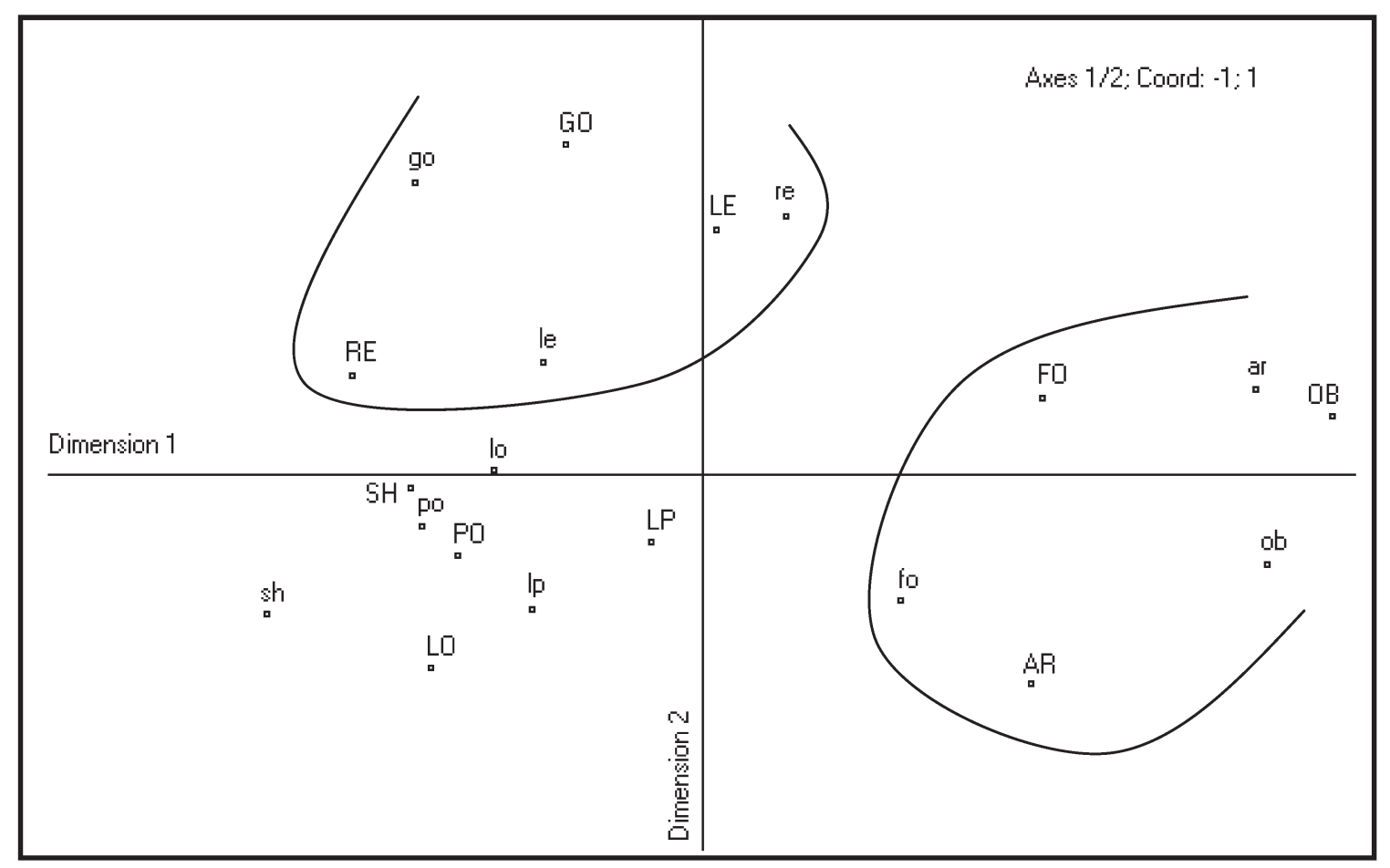

Figure 1. Correspondence analysis of transitional matrix of the controlling activities: Dimensions 1 and 2. Capital letters represent preceding behaviours, small letters following behaviours. Abbreviations are: LP \& lp (look at point), GO \& go (give order), LE \& le (lead), LO \& lo (look at object), SH \& sh (show object), AR \& ar (allow reorientation), RE \& re (reorientation), FO \& fo (follow), PO \& po (point), OB \& ob (obey).

In the correspondence analysis, the first five singular values (with proportion of chi-squared) were: .2143 (38.09\%), .1414 (25.13\%), .0799 (14.21\%), .0545 (9.69\%), and .0302 $(5.38 \%)$. The first two singular values account for $63.22 \%$ of the chi-square and in Figure 1 we can appreciate the distribution of controlling activities in these first two dimensions.

On the first axis, looking first at the preceding controlling behaviours, we observe that the greatest contribution to inertia is made by the activities obey order, follow, and allow reorientation; and within the following controlling behaviours, allow reorientation and obey order contribute the most to the inertia of the first axis. Thus, this first axis could be interpreted as an acquiescent dimension.

On the second axis, the preceding controlling behaviours that contribute more to the inertia are give order and lead, while within the following controlling behaviours these are reorientation and, again, give order. This second axis could be interpreted as an authoritative dimension.

On the other hand, there is also a group of activities close to the origin and not clearly situated in either of the two axes. These are show object, look at object, point, and look at point, both as preceding and following behaviour. Although these activities could make reference to situations in which the subject "directs" or obeys others in some way, our results suggest that these activities are related neither to acquiescent nor authoritative dimensions.

\section{Relationships between controlling and aggressive behaviour}

Based on frequency of authoritative behaviours, 12 children from each subgroup of 4- and 5-year-olds were selected. From each of these subgroups, 6 children with the highest frequency and 6 with the lowest were selected. For each subgroup, an Analysis of Variance was performed to determine the differences in frequency of aggressive behaviour between the individuals of higher values in authoritative behaviour and the lower ones.

Whereas in the subgroup of 4-year-old children, an Analysis of Variance revealed no significant relationship between the frequency of authoritative and aggressive behaviours, $F_{(1,11)}=$ $0.655, p=.4391$, in the subgroup of 5-year-old children, the individuals with the highest values in authoritative behaviours were less aggressive than those with the lowest values, $F_{(1,11)}=$ 6.552, $p=.0284$.

\section{Discussion}

Our results demonstrate the existence of two independent dimensions in controlling activities. The first one we have named as acquiescence, because it includes the activities obey order, follow, and allow reorientation, both as preceding and following activities; and the second dimension we have named as authoritative because it includes give order, lead, and reorientation, also as preceding and following activities. The fact that both preceding and following activities appear in each of the two dimensions allows us to affirm that, during a group activity, the individuals performing authoritative patterns do not exhibit acquiescent behaviours and vice versa.

This result may be suggesting the existence of a division of roles, where some individuals direct or influence the behaviour of others, and other individuals follow the instructions. Thus, it is plausible to conclude that in the organisation of the groups of preschool children, controlling activities are relevant. As well as 
social hierarchies based on aggressive behaviours, it is likely that other hierarchies based more on controlling activities could exist, and it would be interesting for future research to explore this type of hierarchy by analysing the controlling interactions in preschool children.

As Hawley (2002) pointed out, to clarify the role of both types of social behaviours in the development of social structure in childhood, we should shift attention away from the traditional hierarchies based on aggressive interactions. The new point of view would demand an approach more functional than structural (i.e., focusing on the goals related to social hierarchies). Competition for resources is the most frequent elicitor of aggression-based hierarchies (Coie \& Dodge, 1998), but competition for objects or resources is only one of the goals of preschool children (Rubin, Bukowski, \& Parker, 1998). Across ages, children's goals become more and more complex and so children seek to integrate into social groups to carry out coordinated activities as an advanced form of cooperative play (e.g., sociodramatic play, the paradigm case of play for preschoolers; Yawkey \& Pellegrini, 1984). This advanced form of cooperative play requires sophisticated cognitive, emotional, and social skills, and it also contributes greatly to the children's ability to resolve their disputes through negotiation (Garvey, 1990). A strategy based exclusively on aggression probably obstructs the possibility of attaining these goals, so another strategy based on controlling behaviour must emerge.

However, it is plausible to expect a relation between these two forms of group organisation. As a first approach in this study, we have tried to answer the following question: Are the children who perform authoritative behaviour more frequently, and who are probably situated in the higher-rank positions in the controlling hierarchies, the most aggressive ones? To be more specific, and taking into account the decline of aggressive behaviours across the preschool years (Coie \& Dodge, 1998), how does this relationship between authoritative and aggressive behaviours develop from 4 to 5 years old? Whereas some researchers (Strayer, Bovenkerk, \& Koopman, 1975; Strayer \& Harris, 1979) have typified aggressive- and controlling-based hierarchies as independent parameters in the organisational framework of social relationships, the hypothesis of Rubin (2000), that controlling hierarchies have evolved from hierarchies based more on aggressive encounters also seems plausible.

Our results reveal no significant relationships between authoritative and aggressive behaviours in the 4-year-old subgroup. However, in the 5-year-old subgroup, individuals with the highest frequency of authoritative behaviours were less aggressive than individuals with the lowest frequency. These older preschool children use a strategy that consists of displaying a high level of authoritative behaviour and simultaneously low levels of aggressive behaviours, which probably allows them to participate in complex activities. By following this strategy children are able to attain their personal goals without damage to the relationship with peers, which allows them to improve their social competence (Rubin \& RoseKrasnor, 1992).

In any case, the presence (at preschool age) of these controlling hierarchies together with hierarchies more based in aggressive behaviours, make the panorama of social organisation of these groups more complex. It is likely that aggressive and controlling hierarchies are responses to different objectives, the first related to the access to resources (objects), and the second with the typical requirements of the development of complex activities, which require the coordinated participation of group members. The development of children's goals probably determines the change of strategies that facilitate the evolution of social structure from aggressive to controlling hierarchies. Further research focused on the analysis of controlling interactions is needed in order to clarify the development of social hierarchies in preschool children, as pointed out above. As suggested by Eccles, Wigfield, and Schiefele (1998), we consider it essential to preserve the proposed functional approach.

Manuscript received August 2002 Revised manuscript received May 2003 PrEview publication July 2004

\section{References}

Archer, J. (1992). Ethology and human development. Hemel Hempstead, UK: Harvester Wheatsheaf.

Bernstein, I.S. (1981). Dominance: The baby and the bathwater. Behavioral and Brain Sciences, 4, 419-457.

Blurton Jones, N.G. (1967). An ethological study of same aspects of social behaviour of children in nursery school. In D. Morris (Ed.), Primate ethology (pp. 347-368). London: Weidenfeld \& Nicholson.

Blurton Jones, N.G. (1971). Criteria for use in describing facial expressions of children. Human Biology, 43, 365-413.

Blurton Jones, N.G. (1972). Categories of child-child interaction. In N.G. Blurton Jones (Ed.), Ethological studies of child behaviour (pp. 97-127). London: Cambridge University Press.

Boulton, M.J., \& Smith, P.K. (1990). Affective biases in children's perceptions of dominance relationships. Child Development, 61, 221-229.

Brannigan, C., \& Humphries, D.A. (1972). Human nonverbal behaviour as a means of communication. In N.G. Blurton Jones (Ed.), Ethological studies of child behaviour (pp. 37-64). London: Cambridge University Press.

Braza, F., Braza, P., Carreras, M.R., \& Muñoz, J.M. (1997). Development of sex differences in preschool children: Social behavior during an academic year. Psychological Reports, 80, 179-188.

Carreras, M.R. (1999). Adaptabilidad social en niños de 4 y 5 años: Un estudio piloto [in Spanish]. Tesis Doctoral. Cádiz: Servicio de Publicaciones de la Universidad de Cádiz.

Coie, J.D., \& Dodge, K.A. (1998). Aggression and antisocial behavior. In W. Damon (Series Ed.) \& N. Eisenberg (Volume Ed.), Handbook of child psychology, Vol. 3 (pp. 779-862). New York: Wiley.

Eccles, J.S., Wigfield, A., \& Schiefele, U. (1998). Motivation to succeed. In W. Damon (Series Ed.) and N. Eisenberg (Vol. Ed.), Handbook of Child Psychology, Vol. 3 (pp. 1017-1095). New York: Wiley.

Edwards, C.A. (1994). Leadership in groups of school-age girls. Developmental Psychology, 30, 920-927.

Fukada, S., Fukada, H., \& Hicks, J. (1994). Structure of leadership among preschool children. The fournal of Genetic Psychology, 155, 389-395.

Fukada, H., Fukada, S., \& Hicks, J. (1997). The relationship between leadership and sociometric status among preschool children. The fournal of Genetic Psychology, 158, 481-486.

Garvey, C. (1990). Play. Cambridge, MA: Harvard University Press.

Hawley, P.H. (2002). Social dominance and prosocial and coercive strategies of resource control in preschoolers. International fournal of Behavioral Development, 26, 167-176.

Hold, B.C.L. (1977). Rank and behavior: An ethological study of preschool children. Homo, 28, 158-188.

Howes, C. (1990). A comparison of preschool behaviors with peers when children enroll in child care as infants or older children. Vth European Conference on Developmental Psychology, Edinburgh, UK.

LaFreniere, P., \& Charlesworth, W.R. (1983). Dominance, attention and affiliation in a preschool group: A nine-month longitudinal study. Ethology and Sociobiology, 4, 55-67.

Martin, P., \& Bateson, P. (1986). Measuring behaviour, an introductory guide. Cambridge: Cambridge University Press.

McGrew, W.C. (1972a). An ethological study of children's behavior. New York: Academic Press.

McGrew, W.C. (1972b). Aspects of social development in nursery school children with emphasis on the introduction to the group. In N.G. Blurton Jones (Ed.), Ethological studies of child behaviour (pp. 129-156). London: Cambridge University Press. 
Muñoz, J.M. (2000). Social behavior analysis of preschool children during free play time at school: A proposal of modelling. Doctoral dissertation. Cádiz: Cádiz University Press.

Pellegrini, A.D. (2002). Affiliative and aggressive dimensions of dominance and possible functions during early adolescence. Aggression and Violent Behavior, 7, 21-31.

Pettit, G.S., Bakshi, G.S., Dodge, K.A., \& Coie, J.D. (1990). The emergence of social dominance in young boys' play groups: Developmental differences and behavioral correlates. Developmental Psychology, 26, 1017-1025.

Rubin, P.H. (2000). Hierarchy. Human Nature. XV Conference of the International Society of Human Ethology, Salamanca, Spain.

Rubin, K.H., Bukowski, W., \& Parker, J.G. (1998). Peer interactions, relationships, and groups. In W. Damon (Series Ed.) \& N. Eisenberg (Vol. Ed.), Handbook of child psychology in social, emotional and personality development, Vol. 3 (pp. 619-700). New York: John Wiley.

Rubin, K.H., \& Rose-Krasnor, L. (1992). Interpersonal problem solving. In V.B.V. Hassett \& M. Hersen (Eds.), Handbook of social development (pp. 283323). New York: Plenum Press.

Sluckin, A., \& Smith, P. (1977). Two approaches to the concept of dominance in preschool children. Child Development, 48, 917-923.

Smith, P.K., \& Connolly, K.J. (1972). Patterns of play and social interaction in preschool children. In N.G. Blurton Jones (Ed.), Ethological studies of child behaviour (pp. 65-95). London: Cambridge University Press.

Smith, P.K., \& Lewis, K. (1985). Rough and tumble play, fighting and chasing in nursery school children. Ethology and Sociobiology, 6, 175-181.

Strayer, F.F. (1980). Child ethology and the study of preschool social relations. In H.C. Foot, A.J. Chapman, \& J.R. Smith (Eds.), Friendship and social relations in children (pp. 235-265). New York: Wiley.
Strayer, F.F., Bovenkerk, A., \& Koopman, R.F. (1975). Social affiliation and dominance in captive squirrel monkeys (Saimiri scieureus). Fournal of Comparative and Physiological Psychology, 89, 308-318.

Strayer, F.F., Chapeskie, T.R., \& Strayer, J. (1978). The perception of preschoo social dominance relations. Aggressive Behavior, 4, 183-192.

Strayer, F.F., \& Harris, P.J. (1979). Social cohesion among captive squirre monkeys (Saimiri scieureus). Behavioral Ecology and Sociobiology, 5, 93-110.

Strayer, F.F., \& Strayer, J. (1976). An ethological analysis of social agonism and dominance relations among preschool children. Child Development, 47, 980989

Thon, B., \& Chabaud, C. (1986). Act duration as a potential informational parameter in the sequential analysis method. In P.W. Colgan \& R. Zayan (Eds.), Quantitative model in ethology (pp. 129-142). Toulouse: Privat IEC.

Tinbergen, N. (1953). Social behavior in animals. London: Methuen.

Van der Heijden, P.G.M. (1986). Transition matrices, model fitting, and correspondence analysis. In E. Diday (Ed.), Data analysis and informatics IV (pp. 221-226). Amsterdam: North Holland.

Van der Heijden, P.G.M., De Vries, H., \& van Hooff, J.A.R.A.M. (1990). Correspondence analysis of transition matrices, with special attention to missing entries and asymmetry. Animal Behavior, 40, 49-64.

Vaughn, B., \& Waters, E. (1981). Attention structure, sociometric status and dominance: Interrelations, behavioral correlates and relationships to socia competence. Developmental Psychology, 17, 275-288.

Yawkey, T., \& Pellegrini, A.D. (1984). Child's play. Hillsdale, NJ: Lawrence Erlbaum Associates Inc. 